
\title{
25 Research Sourere \\ Childhood Academic Performance: A Potential Marker of Genetic Liability to Autism
}

\author{
Janna L Guilfoyle \\ Northwestern University \\ Molly Winston \\ Northwestern University \\ John Sideris \\ University of Southern California \\ Gary E Marin \\ St John's University \\ Kritika Nayar \\ Northwestern University \\ Lauren Bush \\ Northwestern University \\ Tom Wassink \\ The University of lowa Healthcare \\ Molly Losh ( $\square$ m-losh@northwestern.edu ) \\ Northwestern University https://orcid.org/0000-0002-9823-8249
}

Research

Keywords: Autism spectrum disorder, endophenotype, language, academics, broad autism phenotype

Posted Date: June 18th, 2021

DOI: https://doi.org/10.21203/rs.3.rs-604273/v1

License: (c) (i) This work is licensed under a Creative Commons Attribution 4.0 International License.

Read Full License 


\section{Abstract}

Background: Autism spectrum disorder (ASD) is a highly heritable, genetically complex neurodevelopmental disorder. Genetic liability is often expressed among relatives through subclinical, genetically meaningful traits, or endophenotypes. Studies of parents of individuals with ASD suggest important differences from controls in language-related skills in particular, including evidence that such differences may emerge in childhood, that may serve as early markers of genetic liability to ASD. This study investigated whether developmental academic profiles may be evident among clinically unaffected siblings of individuals with ASD, and possibly constitute developmental endophenotypic markers of ASD genetic risk among relatives.

Methods: Longitudinal, archival academic testing records were studied to characterize developmental profiles in the domains of language, reading, and math, among clinically unaffected siblings of individuals with ASD. Relationships were explored between siblings' childhood academic profiles and subclinical ASD-related traits, and the familiality of such traits.

Results: Results revealed relatively lower performance in language-related academic skills among siblings of individuals with ASD, mirroring patterns previously reported among parents. Relationships were detected between siblings' academic performance patterns and subclinical ASD-related traits in themselves and their parents, and with symptom severity in their sibling with ASD. Language phenotypes were associated in mother-sibling dyads, and rigidity and math performance associated in father-child dyads. Limitations: Data from this study represent a relatively small and racially homogenous group of siblings of individuals with ASD, and as such, replication in a larger more diverse sample should be completed to increase generalizability.

Conclusions: Distinctive profiles of academic development were evident in siblings in language-related skills, mirroring prior findings in parents, suggesting specific and subtle phenotypes that may represent early-emerging indicators of genetic liability to ASD and are measurable in first-degree relatives using standardized academic testing. Results also suggest differential intergenerational transmission of ASDrelated traits between mothers and fathers.

\section{Full Text}

This preprint is available for download as a PDF.

\section{Figures}


Figure 1.
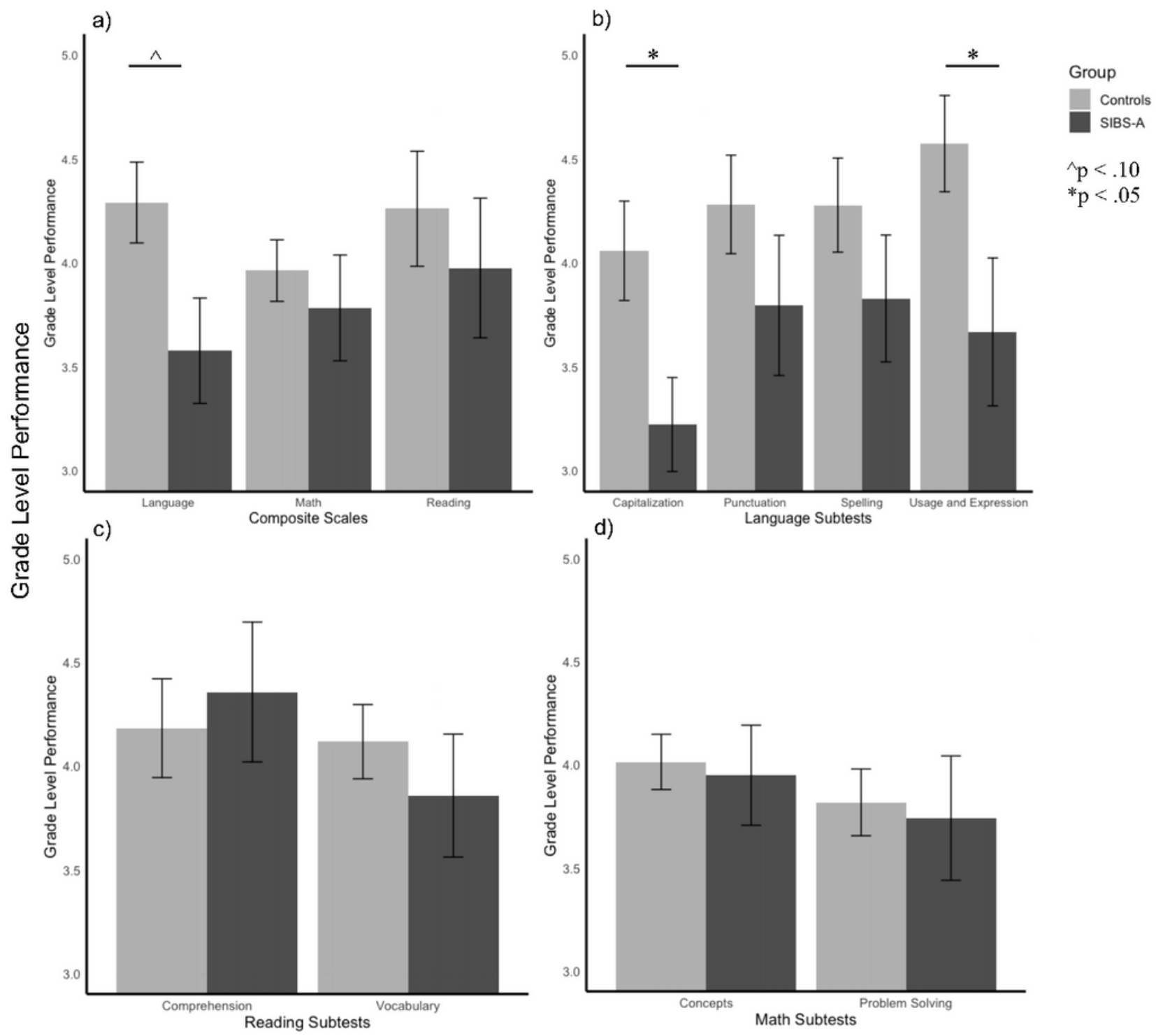

\section{Figure 1}

Figure 1. Estimated grade 3 performance across domains and subtests among SIBS-A and controls. Legend: Groups did not differ across composite scores, though the SIBS-A group trended lower than controls in the language domains $(p=.07)$. The SIBS-A group performed significantly lower than controls on the Capitalization and Language Usage and Expression Subtests $(p<.05, p<.01$, respectively) within the language domain (b), but no differences emerged on reading or math subtests $(c, d)$ 
Figure 2.

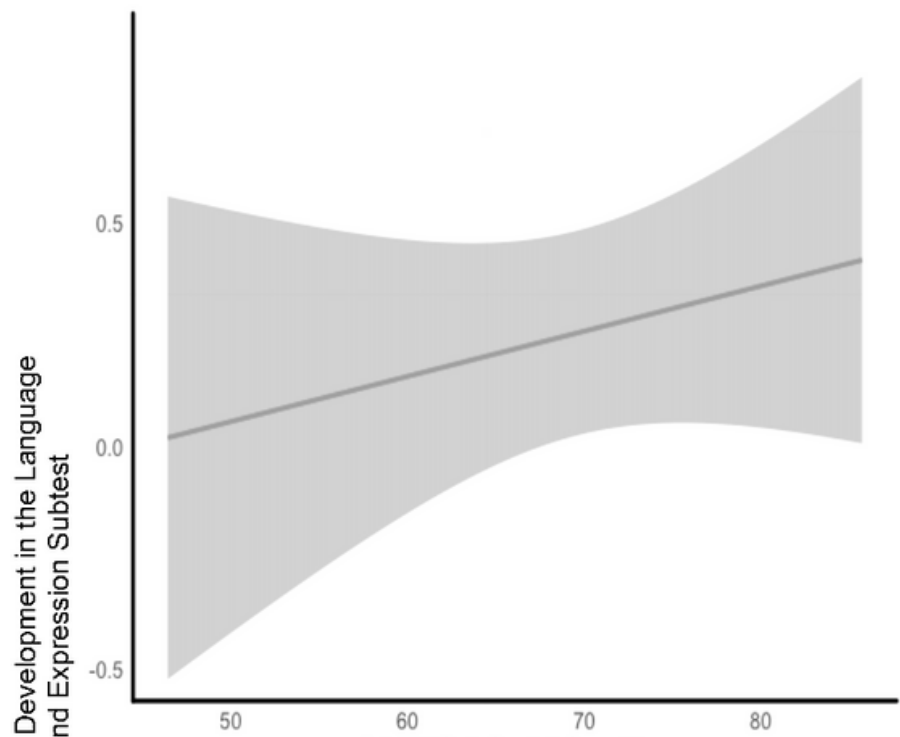

(a) SIBS-A Social Cognition

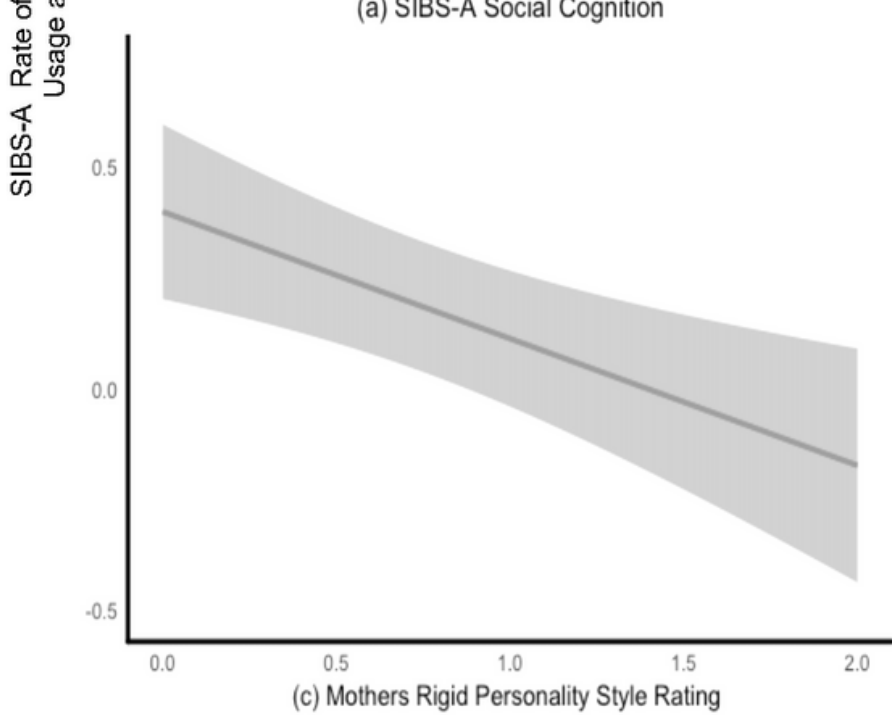

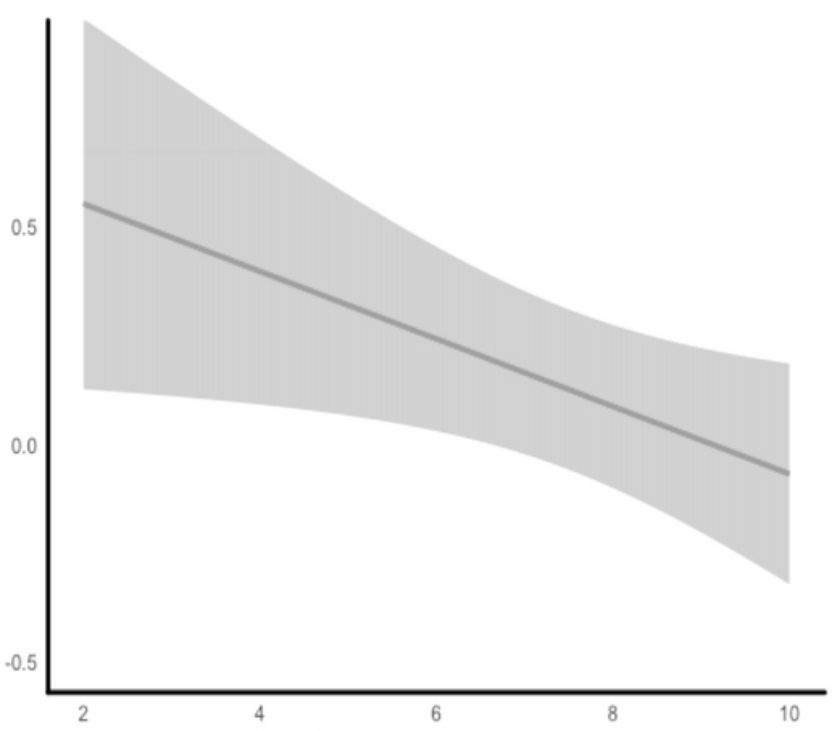

(b) ASD Social Affect Symptom Severity

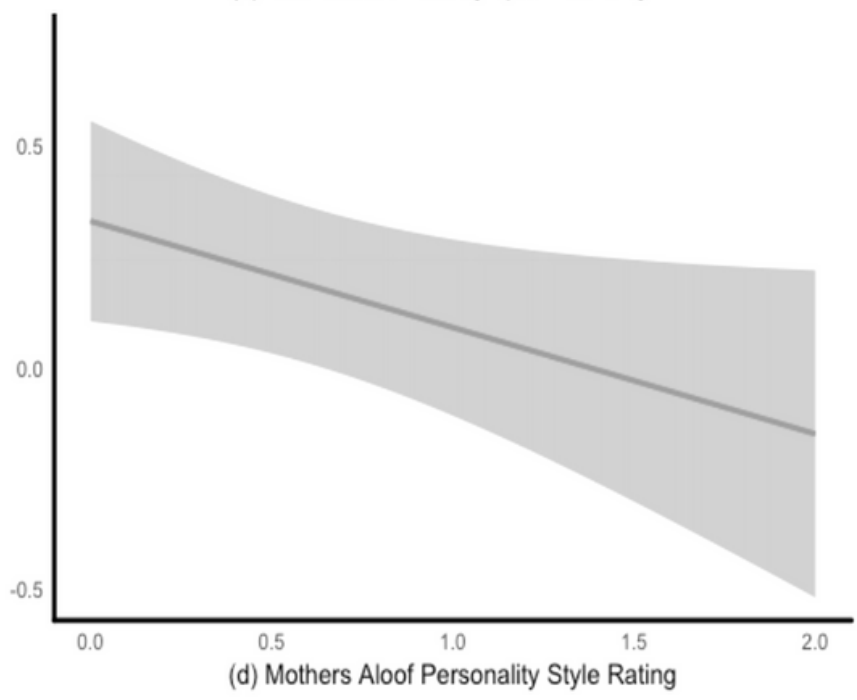

\section{Figure 2}

Figure 2. Associations between SIBS-A language development and clniicial-behavioral features. Legend: Patterns of childhood development on the ITBS language usage and expression subtest among siblings of individuals with ASD are associated with ASD and BAP phenotypes in themselves, their parents, their sibling with ASD. A slower rate of development on this subtest in ASD siblings was significantly associated with (a) poorer performance on a task of social cognition $(r=.53, p<.05)(b)$ increased social affect symptom severity on the ADOS- 2 in their clinically affected sibling $(r=-.57, p<.05)$, and $(c)$ 
increased rigid $(r=-.72, p<.01)$ and $(d)$ aloof personality styles in their mothers $(r=-.54, p<.05$.) The grey shade area represents the $95 \%$ confidence interval

\section{Supplementary Files}

This is a list of supplementary files associated with this preprint. Click to download.

- SibsITBSCoverLetterMA.pdf 